\title{
Disturbance and recruitment: a test of solute and substrate specificity using Mercenaria mercenaria and Capitella sp. 1
}

\author{
Roberta L. Marinelli ${ }^{1, *}$, Sarah Ann Woodin ${ }^{2}$ \\ ${ }^{1}$ Chesapeake Biological Laboratory, University of Maryland Center for Environmental Science, PO Box 38, Solomons, \\ Maryland 20688, USA \\ ${ }^{2}$ Department of Biological Sciences and Marine Science Program, University of South Carolina, Columbia, \\ South Carolina 29208, USA
}

\begin{abstract}
Disturbances alter sediment surface chemistry, and this alteration promotes rejection of habitats by new benthic recruits. To date, the specific compound(s) affecting the rejection response have not been identified, but model predictions and experimental evidence suggest that oxygen and ammonium concentrations are informative. We evaluated the recruitment response of the opportunistic polychaete Capitella sp. 1 to disturbed, undisturbed and recovering sediments, with parallel measures of oxygen concentration at the sediment surface. Results suggest that Capitella sp. 1 avoid disturbed sediments, but the behavior was not consistent with surface oxygen concentration. We also manipulated porewater ammonium concentration and examined the recruitment responses of Mercenaria mercenaria and Capitella sp. 1 to experimentally altered, as well as naturally disturbed, surfaces. Results suggest that $M$. mercenaria avoid disturbed habitats, regardless of ammonium concentration; however, Capitella sp. 1 responses were consistent with avoidance of high ammonium environments. Finally, we tested a prediction of our disturbance recovery model: that chemical signals associated with disturbance, and responses of recruits, vary as a function of the diagenetic regime. As predicted, chemical concentrations were more dramatically changed in disturbed muds relative to disturbed sands. Capitella sp. 1 rejected disturbed mud surfaces having high ammonium/low oxygen but accepted habitats having low ammonium and high oxygen, including undisturbed mud and sand surfaces, and disturbed sand surfaces. $M$. mercenaria rejected disturbed sediments regardless of ammonium or oxygen concentration, or sediment type. Our findings confirm that small-scale geochemical processes that are widespread in sedimentary habitats affect recruitment decisions.
\end{abstract}

KEY WORDS: Disturbance $\cdot$ Recruitment $\cdot$ Capitella $\cdot$ Mercenaria $\cdot$ Ammonium $\cdot$ Oxygen Resale or republication not permitted without written consent of the publisher

\section{INTRODUCTION}

New recruits into sediments make decisions concerning site acceptability based in part on signals available at the sediment surface. These signals may relate to the particulate phase and include characters such as sediment grain size or organic carbon quality (Pawlik 1992, Cohen \& Pechenik 1999). They also may relate to the dissolved phase and include the presence or absence of freely diffusing or adsorbed molecules associated with the presence of food, conspecifics, competitors or predators (Wilste 1980, Highsmith 1982, Suer \& Phillips 1983, Woodin et al. 1993, Hardege et al. 1998). Alternatively, signals may relate to processes, such as the nature and intensity of disturbance, which are mediated through alteration of surface features (Woodin et al. 1995, Snelgrove et al. 2001b, Marinelli \& Woodin 2002). In such cases, the signals are potentially the proximate cue, with the process being the ultimate selective factor. In all cases, the availability of signals and their effects on recruits are significantly influenced by transport and reaction processes operating 
over a variety of scales. For example, grain size, organic content, and the arrival of new juveniles at a habitat will be influenced by boundary-layer processes operating above the sediment-water interface, at length scales of centimeters to meters (Eckman 1983, Snelgrove et al. 1993). At the same time, solute gradients and concentrations in near-surface sediments are determined by transport and reaction processes operating over depth scales of millimeters to centimeters (Thamdrup et al. 1994).

Given the importance of various chemical signals in sedimentary environments, it is imperative to further characterize the processes that control their distribution and, ultimately, their effectiveness. Such investigations clarify the overall importance of chemical signals in aquatic environments and the extent to which they impact recruitment, as well as processes such as foraging activity (Finelli et al. 2000) and reproductive success (Burke 1986, Hardege \& Bentley 1997). In past publications, we have suggested that the interplay between disturbance and the transport and reaction processes associated with normal organic-matter diagenesis provides a signal that new recruits use to identify, and perhaps avoid, areas that are impacted by physical or biological disruption. Our evidence includes: (1) paired measures of behavior of new recruits and concentrations of oxygen and ammonium in the surface and upper few mm of sediments of disturbed, undisturbed and recovering surfaces (Marinelli \& Woodin 2002); (2) experimental alteration of ammonium alone, with observations of recruit behavior on surfaces with elevated versus normal ammonium concentrations in slurry and porewater replacement experiments (Woodin et al. 1998); and (3) numerical models of time-dependent oxygen and ammonium concentrations in surface sediment layers when sediments are disturbed and allowed to recover (Woodin et al. 1998, Wethey et al. 2001). Physical disturbances tend to occur over relatively large spatial and infrequent temporal scales ( $\mathrm{m}$ to $\mathrm{km}$ and wk to mo; Miller \& Sternberg 1988, Commito et al. 1995), whereas biogenic disturbances occur with some spatial fidelity and at relatively small and frequent scales, i.e. those associated with organism activities such as feeding or defecation (mm to $\mathrm{cm}$ and min to $\mathrm{h}$; Thayer 1983, Krager \& Woodin 1993). However, both classes of disturbance affect surface chemistry (Fanning et al. 1982, Marinelli 1992) and could cause mortality (e.g. via predation, burial, or transport to undesirable sites) for newly settling organisms. As diagenetic processes are widespread among sedimentary environments with active macrofaunal communities, have been prevalent through much of geologic time, and are associated with mortality processes, selection for the ability to detect diagenetic cues would be expected.
An important question is whether avoidance of disturbances at the new juvenile stage is useful, as many sedimentary environments that experience small- and large-scale disruptions are successfully inhabited by adults of the same species. Avoidance may be stage dependent, reflecting shifts in vulnerability to specific sources of mortality. For example, juveniles are more susceptible than adults to ingestion by small fish, suspension-feeders and surface-deposit feeders (Andre \& Rosenberg 1991, Osman et al. 1992); suffocation due to burial (Woodin \& Marinelli 1991) or shell dissolution (Green et al. 2004). With attainment of a larger size, and the ability to burrow more competently and more deeply (Ross et al. 2003), sediment-dwelling organisms become less vulnerable. Moreover, older juveniles and many infaunal adults are capable of secondary dispersal (Emerson \& Grant 1991, Hiddink \& Wolff 2002, Huxham \& Richards 2003), and can move to more favorable locations when size and circumstances (e.g. the flow environment, Butman et al. 1988) permit. Therefore, avoidance of disruption at an early and vulnerable stage, combined with the ability to relocate (e.g. Gunther 1992), is potentially an important strategy for enhancing survivorship in coastal environments. Therefore, it would not be inconsistent for new juveniles to avoid habitats where adults are successfully established. Such distributions of adults and juveniles are typical of several large polychaetes which disrupt the sediment surface (Nicolea zostericola: Eckelbarger 1974, Arenicola marina: Beukema \& de Vlas 1979). Regrettably, few studies in sediments have examined the extent to which settlement choice affects growth and reproductive output beyond metamorphosis (see Cohen \& Pechenik 1999). Until such studies are undertaken, the utility of positive and negative settlement responses remains speculative.

The specificity of diagenetic signals, i.e. which compounds are 'useful' and at what concentration levels, is not well characterized. The utility of the signal among sedimentary environments also remains unassessed. Our diagenetic model suggests that some solutes have a higher likelihood of providing disturbance information (R. L. Marinelli \& S. A. Woodin unpubl. numerical simulations) and predicts a linkage between the significance of the disturbance-diagenetic cues and the sedimentary regime (Woodin et al. 1998). For example, in comparatively organic-rich muddy environments with steep concentration gradients near the sediment surface, disturbance results in a large concentration change at the sediment surface. A relatively long time $(>10 \mathrm{~h})$ is required to return to a concentration more characteristic of an undisturbed surface layer. The converse is true in sands. In such environments, gradients are stretched over significantly longer length scales, disturbance does not produce a large chemical signal 
at the sediment surface, and recovery times are comparatively short. As such, we proposed that diagenetic cues as indicators for disturbance would be more reliable and more effective in muds relative to sands. The recognition of porewater advection as an important transport process in sands further supports this prediction, as gradients are diminished by the advective flushing of surface layers (Huettel et al. 1996, Marinelli et al. 1998).

Below we describe a series of laboratory experiments that extend the number of species of new recruits that respond to disturbed sediment surfaces, and test explicitly 2 predictions generated by the disturbancerecovery model: the role of specific dissolved substances associated with organic matter diagenesis, and the strength of the disturbance response as a function of the sedimentary regime. We tested the behavior of the opportunistic polychaete Capitella sp. 1 (hereafter referred to as Capitella) on intact, disturbed and recovering sediment surfaces, with parallel measures of oxygen concentration at the sediment-water interface. Capitella is widely reported to occupy disrupted habitats (Diaz \& Rosenberg 1995) in which other common coastal species are absent or in very low abundance, and, as such, it is possible that new Capitella recruits may respond positively to recently disturbed sediments, in opposition to the rejection behavior previously reported for Mercenaria mercenaria and Arenicola cristata. We also present laboratory experiments that explicitly test the effect of ammonium concentration in the upper sedimentary layers (top 2 to $3 \mathrm{~mm}$ ) on recruitment responses of Capitella and M. mercenaria (hereafter referred to as Mercenaria). In these experiments, we replaced the topmost layer of porewater with seawater containing ammonium at known concentrations, and compared these responses to those with disrupted and intact surfaces with natural ammonium concentrations. We use data from these same experiments to compare the relative importance of oxygen (which was measured but not successfully manipulated) versus ammonium (which was both manipulated and measured) to new recruits. These comparisons provide insights regarding the specificity of recruitment signals amidst the complex of dissolved substances present in sediment surfaces. Finally, we describe laboratory experiments that test our hypothesis concerning the relative importance of diagenetic cues among sedimentary regimes for Capitella and Mercenaria new juveniles.

\section{MATERIALS AND METHODS}

Test organisms. New recruits of the polychaete Capitella originated from the continuous culture main- tained in the laboratory of Dr. J. Grassle at Rutgers University. Capitellids were maintained in fine sand and fed small amounts of mixed-grain baby cereal every 3 to $4 \mathrm{~d}$. New juveniles were obtained by teasing apart brood tubes, which encouraged release of competent recruits. Mercenaria were obtained from SeaPerfect Sea Farms in Charleston, South Carolina as 14-d-old pediveligers and were maintained in culture on a diet of Isochrysis galbana. Metamorphosis to the benthic stage, as indicated by loss of the velum and cessation of swimming, generally occurred between Days 14 and 18. Only individuals that shed their velum, and thus were competent to assume a benthic existence, were used in experiments, and only within $48 \mathrm{~h}$ of initiation of metamorphosis. Both Mercenaria and Capitella have cosmopolitan distributions in coastal habitats, are known to occur in muds and sands, and have been observed at the locations where sediment was collected for experiments.

Capitella responses to disturbed, intact and recovering cores. Our procedure for evaluating the response of new juveniles to sediment surfaces followed the protocol described in Marinelli \& Woodin (2002), and is briefly reiterated here. In August of 1999, sediment was collected from the lee side of Little Tybee Island $\left(32^{\circ} 0^{\prime} \mathrm{N}, 80^{\circ} 51^{\prime} \mathrm{W}\right.$, organic carbon content $1.17 \pm 0.12 \%[\mathrm{SD}]_{;}$organic nitrogen content $0.13 \pm$ $0.017 \%$ ) in Savannah, Georgia, a muddy sand flat which contains a diverse fauna including infaunal echinoderms (e.g. Amphiopholus and Leptosynapta), and maldanid, onuphid and pectinariid polychaetes. Collection was confined to the top $2 \mathrm{~cm}$ of sediment, and areas of disturbance such as fecal mounds, tubes and feeding traces were avoided. Sediments were returned to Skidaway Institute of Oceanography, sieved through a $1 \mathrm{~mm}$ sieve, and stored in holding tanks immersed in running seawater at ambient temperature. Sediments equilibrated for $3 \mathrm{wk}$. During this time, solute gradients developed, and the oxic layer reached approximately 1 to $2 \mathrm{~mm}$ depth below the sediment surface.

Sediment cores for experiments were obtained by inserting a small plastic core barrel $(4.0 \mathrm{~cm}$ length, $2.5 \mathrm{~cm} \mathrm{ID)} \mathrm{into} \mathrm{the} \mathrm{equilibrated} \mathrm{sediment,} \mathrm{removing}$ the core and sealing the bottom. Cores were placed in a continuously aerated, filtered $(3 \mu \mathrm{m})$ seawater bath at ambient temperature until used in experiments, generally within several hours of collection. The seawater in the bath was changed every few hours to ensure that metabolites did not accumulate.

Sediment cores were subsequently manipulated to achieve 4 conditions: disturbed, $1 \mathrm{~h}$ recovery, $5 \mathrm{~h}$ recovery, and control. In disturbed cores, the top $3 \mathrm{~mm}$ of sediment was removed using a small spatula. In recovering cores, the sediments were disturbed 
according to the method described, and then allowed to 'recover' (i.e. re-equilibrate) for a specified time period, either 1 ( $1 \mathrm{~h}$ recovery) or $5 \mathrm{~h}(5 \mathrm{~h}$ recovery). Control cores were left undisturbed. All manipulated and control cores were maintained in aerated, circulating seawater until used in experiments. For disturbed cores, behavioral responses to the sediment surface were recorded immediately after the disturbance event. For recovery cores, behavioral responses were assessed after the specified recovery time. There were 8 experimental replicates for each sediment surface type. We measured both the surface concentration of oxygen and depth of the oxic layer in each experimental core at the time of behavioral measurements. The behavioral assays and the protocol for oxygen measurements are described below.

Mercenaria and Capitella responses to manipulated surfaces. We tested the behavioral responses of new juveniles to core surfaces in which ammonium concentration had been experimentally altered. These trials were conducted in August of 2000, at the Baruch Institute Field Laboratory, University of South Carolina, Georgetown, South Carolina. Cores were collected from Oyster Landing $33^{\circ} 22^{\prime} \mathrm{N}, 79^{\circ} 18^{\prime} \mathrm{W}$, an intertidal flat that contains both muddy and sandy regions. The organic carbon and nitrogen content of Oyster Landing sediments has a considerable range, e.g. 0.36 to $0.7 \%$ $( \pm 0.17 \% \mathrm{SD})$ and 0.03 to $0.05 \%( \pm 0.01 \% \mathrm{SD})$ respectively, due to local variation in grain characteristics (250 to $375 \mu \mathrm{m}$ median grain diameter, moderately sorted: Marinelli \& Woodin 2002). Locations containing large macrofauna or other obvious disturbances to the sediment surface were avoided. The plexiglass core barrel had an inner diameter of $6 \mathrm{~cm}$, a wall thickness of $0.6 \mathrm{~cm}$, and length of $6 \mathrm{~cm}$. Cores were sealed with a double o-ringed solid PVC stopper $(6 \mathrm{~cm}$ wide by $2 \mathrm{~cm}$ thick) inserted at the base of the barrel; the resulting length of the sediment core was approximately $4 \mathrm{~cm}$. Each core barrel was fit with a series of self-sealing rubber septa at $0.5 \mathrm{~cm}$ intervals, as described in Marinelli et al. (1998). These ports allowed collection and manipulation of porewater in relatively porous sandy sediments using a needle and syringe assembly, described below. Sediment cores were taken such that surfaces were flush with the upper lip of the core. The cores were returned immediately to the laboratory and used within $12 \mathrm{~h}$ of collection.

Seawater solutions containing elevated ammonium concentrations were prepared by adding ammonium chloride to $3 \mu \mathrm{m}$ filtered seawater obtained from the Baruch Laboratory seawater system. We also attempted to evaluate the relative importance of surface and subsurface oxygen concentrations in sediments because our prior experiments suggested a relationship between the oxygen gradient and recruit be- havior; however, this manipulation failed. Thus, our experiments included seawater solutions containing combinations of high (100 to $200 \mathrm{\mu mol} \mathrm{l}^{-1}$ ) or low (ambient, approximately $10 \mu \mathrm{mol} \mathrm{l}^{-1}$ ) ammonium with ambi-

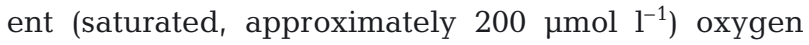
concentrations. The core surfaces thus consisted of high ammonium, high oxygen (HAHO), and low ammonium, high oxygen (LAHO) treatments.

Sand cores were selected for porewater manipulation due to the ease of withdrawing porewater in permeable sediments. The ambient porewater in the top half $\mathrm{cm}$ of the core was withdrawn by inserting an 18 gauge needle (attached to a syringe) into the uppermost rubber septum and removing the entire upper half $\mathrm{cm}$ of porewater. At the same time, we slowly dripped one of the prepared solutions onto the core surface to replace the withdrawn pore fluid. When the replacement was complete, we placed the core into a large culture dish containing fully oxic seawater. The core surface was fully covered with a $1 \mathrm{~cm}$ layer of fresh overlying water, such that new recruits could be added for behavioral assays. There were 5 experimental replicates for each HAHO and LAHO treatment.

Behavioral assays and determination of oxygen and ammonium concentrations in cores from Oyster Landing are described below.

The importance of diagenetic cues among sedimentary regimes. Sediments from muddy and sandy habitats were collected from Oyster Landing using the same technique described above, and returned to the laboratory within $1 \mathrm{~h}$ of collection. A total of 20 cores were obtained, 10 from muddy regions, and 10 from sandy regions, and placed in a holding tank with filtered, aerated running seawater. Cores from both mud and sand habitats were designated as 'disturbed' or 'control' by random selection, such that there were 5 replicates in each of the control mud (CM), control sand $(\mathrm{CS})$, disturbed mud (DM) and disturbed sand (DS) treatments. As in previous experiments, disturbed cores were established by removing the top $3 \mathrm{~mm}$ of sediment, using a spatula. Control cores were not modified. All disturbances of designated disturbed cores were imposed immediately prior to evaluation of the responses of new recruits. We evaluated 1 Mercenaria and 1 Capitella on each core surface in separate, consecutive trials, but in different locations of the core. This test also served to confirm that our ammonium manipulations, described above, were suitable mimics to disturbed and control surfaces of natural sediments containing intact porewater gradients.

Behavioral assays. For new juvenile trials, an individual was taken from the culture, pipetted gently into the water column, and allowed to drift onto the sediment surface. Responses to sediment surfaces (behaviors classified as acceptance or rejection) were 
recorded over a $6 \mathrm{~min}$ period. This time interval is approximately $10 \times$ the average time required for new Mercenaria juveniles to burrow into acceptable sediment; Capitella juveniles tend to burrow more rapidly (S. A. Woodin pers. obs.). In unacceptable sediments, individuals of both species remain on the sediment surface, which, in flowing water, may result in advection away from the site (Woodin et al. 1995). Failure to burrow within a 6 min observation window is taken as evidence of habitat rejection.

For both species, all exploratory behaviors were recorded, but the principal measure of acceptability is the amount of time spent on the sediment surface (time on surface, or TOS). For acceptable sediments, the time spent on the surface is comparatively short because burrowing commences relatively soon after the individual reaches the sediment surface. In those cases, TOS is the time prior to initiation of burrowing. In unacceptable habitats, burrowing may be delayed, or the individual may refuse to burrow. In the latter case, the time spent on the surface is equal to the total time of the observation period.

Chemical measurements. Clark-style oxygen microelectrodes (purchased from Diamond General, see Revsbech et al. 1981 for a description of the technology) were used to measure oxygen (all experiments). For the sediment-surface concentration, 3 point measurements were made, all within a few $\mathrm{cm}$ of the location where recruit responses were evaluated. In addition, one sediment oxygen profile was taken for each core. The location of the sediment-water interface was determined by examining electrode position through a dissecting microscope at $10 \times$ magnification. All oxygen measurements were obtained under low light conditions, and there were no indications of oxygen evolution due to benthic photosynthesis. In addition, there was no evidence of development of a stagnant boundary layer (i.e. reduction in oxygen concentrations in the mms above the sediment surface), suggesting that our procedure for storing and evaluating sediment cores did not produce significant experimental artifacts. Calibration of the electrode was accomplished by nitrogen bubbling of seawater to produce samples of varying oxygen saturation, measurement of the amperometric signal, and then determination of actual oxygen concentration in the sample using Winkler titration. Standard curves were calculated by regression of amperometric reading versus concentration using 4 data points. This method typically yielded statistically significant slopes with $\mathrm{r}$-square values $>0.95$. Calibrations were run every few hours so that any drift in the electrode could be detected, and the appropriate corrections applied.

For the experiments conducted at the Baruch Laboratory, measurements included oxygen concentration (using microelectrodes, see description above), ammonium concentration in the water column (collection of water overlying the core surface with subsequent colorimetric analysis), and porewater ammonium concentration in the top 2 to $3 \mathrm{~mm}$ of sediment. The method of porewater collection was determined by sediment type. For sands, the overlying water was siphoned from the core using a syringe and needle. Subsequently, porewater was collected by inserting a gastight syringe assembly with an 18 gauge needle into the rubber septum port of the core barrel that was located closest to the sediment surface, usually within $2 \mathrm{~mm}$ of the sediment-water interface. Porewater was collected by slowly pulling on the plunger. Assuming 50 to $60 \%$ porosity (a reasonable number for most sands), collection of $2 \mathrm{ml}$ of fluid should correspond to the upper 1 to $2 \mathrm{~mm}$ of porewater. Porewater from muds was obtained via extrusion and sectioning of the top $2 \mathrm{~mm}$, centrifugation and collection of the supernatant. All porewater samples were filtered through a $0.45 \mu \mathrm{m}$ Acrodisc filter prior to analysis. Ammonium concentrations were determined using the colorimetric method described by Koroleff (1976).

Statistical analysis. All data were checked for normality, homogeneity of variance, and residuals. If necessary the data were either log- or square-root transformed prior to analysis. Statistical analyses were conducted using SAS.

Capitella responses to disturbed, intact and recovering cores: ANOVA was conducted to determine whether oxygen concentrations on sediment surfaces and TOS (the indicator of sediment acceptability) varied as a function of the imposed treatments. Because Capitella is an opportunistic polychaete, responses to disturbance may or may not have followed avoidance of disturbed surfaces as in prior experiments with Mercenaria and Arenicola. Thus we conducted a posteriori multiple comparisons to examine differences in response to treatments as a function of the manipulations.

Mercenaria and Capitella responses to natural and manipulated surfaces: We conducted ANOVA using all data from the Oyster Landing cores for which we had paired measures of ammonium concentration and TOS (CM, DM, CS, DS, HAHO, LAHO). For these experiments, we had a set of clear orthogonal predictions and used linear contrasts to test the hypotheses listed in Table 1. Our general approach was to test for differences in geochemical properties, and then determine whether behavior (TOS) was consistent with differences in surface chemistry. Although we were not able to specifically manipulate oxygen concentrations (see above), we had measures of oxygen concentration for each of the treatments listed above. We used these data to conduct a separate analysis of the response of new recruits to oxygen concentrations in surface sedi- 
Table 1. Mercenaria mercenaria and Capitella sp. 1. ANOVA linear a priori contrasts plus expected and observed results for experiments with oyster landing sediments. Results are given for the chemical variable (ammonium concentration or oxygen concentration), sediment variable (sand or mud) and behavioral data (TOS) for new recruits of Mercenaria and Capitella. Exp = expected, Obs = observed, TOS $=$ time on surface, $\mathrm{CM}=$ control mud, $\mathrm{DM}=$ disturbed mud, $\mathrm{CS}=$ control sand, $\mathrm{DC}=$ disturbed sand, LAHO = low ammonium, high oxygen, HAHO = high ammonium, high oxygen, Merc = Mercenaria, Cap = Capitella, Disturb $=$ disturbance effect beyond alteration of oxygen and ammonium, Manip = manipulation. ${ }^{*} p=0.05,{ }^{* *} p=0.01,{ }^{* * *} p \leq 0.001$, ns $=$ not significant

\begin{tabular}{|c|c|c|c|c|c|c|}
\hline \multirow[t]{2}{*}{ Effect } & \multirow[t]{2}{*}{ Contrast } & \multicolumn{2}{|c|}{ Sediment condition } & \multicolumn{2}{|c|}{- TOS } & \multirow[b]{2}{*}{$\begin{array}{l}\text { Obs } \\
\text { Cap }\end{array}$} \\
\hline & & Exp & Obs & $\operatorname{Exp}$ & $\begin{array}{c}\text { Obs } \\
\text { Merc }\end{array}$ & \\
\hline \multicolumn{7}{|l|}{ Ammonium } \\
\hline$\left[\mathrm{NH}_{4}\right]:$ & $\mathrm{CM}+\mathrm{CS}+\mathrm{DS}+\mathrm{LAHO}=\mathrm{DM}+\mathrm{HAHO}$ & $*$ & $* * *$ & ${ }^{*}$ & ${ }^{* *}$ & $* * *$ \\
\hline Disturb control: & $\mathrm{CM}+\mathrm{CS}=\mathrm{DS}$ & ns & $\mathrm{ns}$ & ns & $* *$ & ns \\
\hline Manip control: & $\mathrm{CM}+\mathrm{CS}=\mathrm{LAHO}$ & ns & ns & ns & ns & ns \\
\hline \multicolumn{7}{|l|}{ Oxygen } \\
\hline Disturb control: & $\mathrm{CM}+\mathrm{CS}=\mathrm{DS}$ & ns & $\mathrm{ns}$ & ns & ** & ns \\
\hline Manip control: & $\mathrm{CM}+\mathrm{CS}=\mathrm{LAHO}$ & ns & ns & ns & ns & ns \\
\hline Oxygen + disturb: & $\mathrm{CM}+\mathrm{CS}+\mathrm{DS}+\mathrm{HAHO}+\mathrm{LAHO}=\mathrm{DM}$ & ${ }^{*}$ & $* * *$ & ${ }^{*}$ & $* * *$ & $* * *$ \\
\hline \multicolumn{7}{|l|}{ Sediment type } \\
\hline Sand: & $\mathrm{CM}+\mathrm{CS}=\mathrm{DS}$ & $\mathrm{ns}^{\mathrm{a}}$ & $\mathrm{ns}^{\mathrm{a}}$ & ns & $* *$ & ns \\
\hline Mud: & $\mathrm{CM}+\mathrm{CS}+\mathrm{DS}=\mathrm{DM}$ & $*$ & $* * \mathrm{~b} * * * \mathrm{c}$ & $*$ & $* *$ & $* * *$ \\
\hline
\end{tabular}

ments, recognizing that low oxygen treatments overlap the disturbance treatments. If some other element of the experiment is the driving force behind recruit behavior, this would be revealed by a significant difference in TOS for the disturbance control contrast CM $+\mathrm{CS}=\mathrm{DS}$, or the porewater manipulation control contrast $\mathrm{CM}+\mathrm{CS}=\mathrm{LAHO}$, but no parallel responses in TOS for the ammonium and oxygen contrasts (Table 1).

The importance of diagenetic cues among sedimentary regimes: We predicted that for both ammonium and oxygen, CM, CS, and DS surfaces should be geochemically similar to one another but different from DM surfaces, and that recruit behavior would vary accordingly (Table 1). We used ANOVA to look for significant differences in oxygen, ammonium, and TOS as a function of each treatment, and orthogonal contrasts to test our predictions in terms of chemistry and behavior (Table 1).

\section{RESULTS}

\section{Capitella responses to disturbed, intact and recovering cores}

Concentrations of oxygen in disturbed and recovering cores were consistent with the prediction that disturbance causes a dramatic change in surface oxygen concentration, and that recovery occurs on the order of hours (Fig. 1). Average surface oxygen values in control cores were approximately $110 \mu \mathrm{mol} \mathrm{l^{-1 }}$, whereas values for disturbed, 1 and 5 h recovery were 48, 88 and $122 \mu \mathrm{mol} \mathrm{l^{-1 }}$, respectively. The ANOVA showed significant differences in oxygen concentration among treatments $\left(\mathrm{p}<0.0001, F_{3,28}=64.92\right)$. Tukey's multiple comparison procedure revealed that control and $5 \mathrm{~h}$ recovery cores were different from $1 \mathrm{~h}$ recovery cores, which were different from disturbed cores. This order is consistent with our expectations based on general diagenetic theory.

Individuals varied in TOS among treatments (Fig. 1). On average, new recruits burrowed immediately into

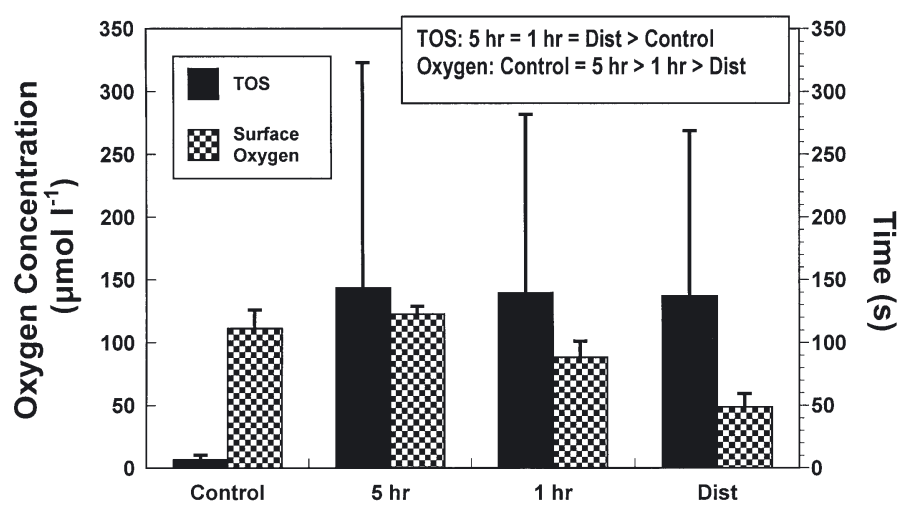

Fig. 1. Capitella sp. 1. Effect of Capitella responses to Tybee Island sediments that were undisturbed (control), disturbed, or in 1 of 2 stages of post-disturbance recovery ( $1 \mathrm{~h}$ recovery, $5 \mathrm{~h}$ recovery). Data are means $(\mathrm{n}=8)$ and SDs of surface oxygen concentration and time on surface prior to initiation of burrowing. TOS: time on surface; Dist: disturbed 
control sediments $($ TOS $=7 \mathrm{~s}$ ), but took longer in disturbed $(137 \mathrm{~s}), 1 \mathrm{~h}$ recovery $(140 \mathrm{~s})$ and $5 \mathrm{~h}$ recovery $(143 \mathrm{~s})$. ANOVA revealed significant differences among treatments $\left(\mathrm{p}<0.0001, F_{3,28}=9.97\right)$. Tukey's multiple comparison procedure showed that TOS for controls was significantly lower than all other treatments. This finding suggests that disturbed cores remained unacceptable well after oxygen concentrations had returned to pre-disturbance levels, and that some other factor associated with disturbance that was not measured may have caused the rejection behavior.

\section{Mercenaria and Capitella responses to manipulated and natural surfaces}

\section{Surface chemistry}

Replacement of porewater in sandy cores with ammonium-spiked seawater successfully elevated ammonium concentrations in the upper few $\mathrm{mm}$ of sediment porewater in sands, relative to the control solution. In HAHO and LAHO cores, average ammonium concentrations in the upper 2 to $3 \mathrm{~mm}$ of sediments were 144 and $10 \mu \mathrm{mol} \mathrm{l}^{-1}$, respectively (Fig. 2). By comparison, DM surfaces were lower, averaging

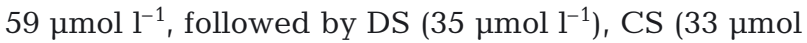

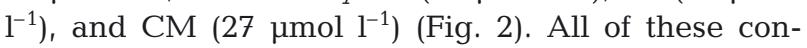
centrations are within the range of naturally occurring ammonium concentrations in shallow field sediments (see Woodin et al. 1998). ANOVA showed significant differences in porewater ammonium concentration among core types $\left(p=0.0001, F_{5,24}=26.5\right)$. The orthogonal contrast results supported our prediction (Table 1) that control muds and control sands would not be different from disturbed sands (CM + $\mathrm{CS}=\mathrm{DS}, \mathrm{p}=0.6745, F=0.18)$ or the manipulated LAHO sediments $(\mathrm{CM}+\mathrm{CS}=\mathrm{LAHO}, \mathrm{p}=0.0928, F=$ 3.06) (Fig. 2). We also expected that disturbed muds would be similar to our ammonium-spiked surfaces; the spiked surfaces were higher. These concentrations, however, are by no means extraordinary. Orthogonal contrasts also supported our expectation that ammonium concentrations in CM, CS, DS and LAHO cores would be similar to one another, but different from the DM and HAHO cores $(\mathrm{CM}+\mathrm{CS}+$ $\mathrm{DS}+\mathrm{LAHO}=\mathrm{DM}+\mathrm{HAHO})(\mathrm{p}=0.0001, F=87.1)$. Finally, ammonium concentrations in the water surrounding the cores was low (approx. $10 \mu \mathrm{mol} \mathrm{l}^{-1}$ ), and oxygen concentrations remained high (approx. $200 \mu \mathrm{mol} \mathrm{\textrm {l } ^ { - 1 }}$ ). In essence, we successfully manipulated the porewater ammonium environment in the intended directions, and within the range of naturally occurring concentrations, while keeping overlying

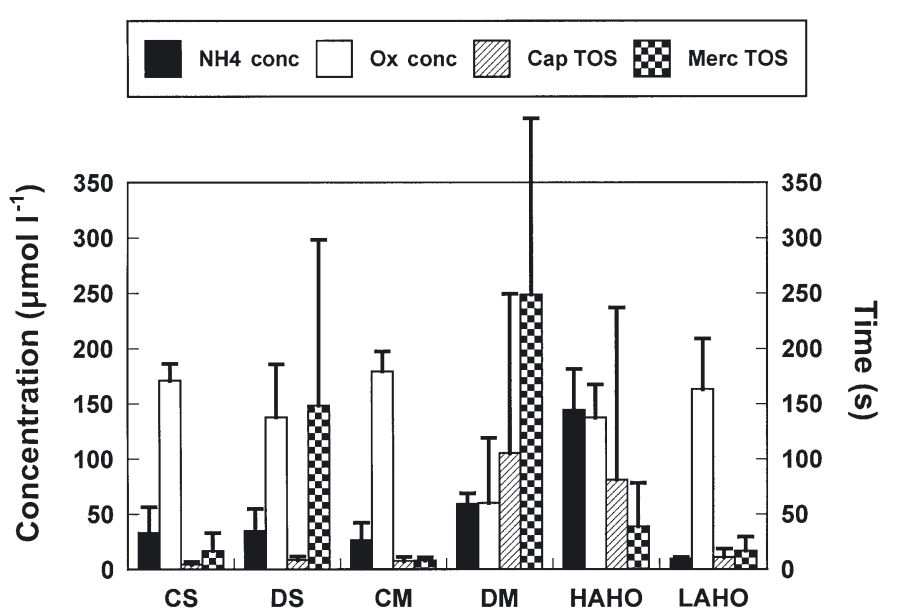

Fig. 2. Capitella sp. 1 and Mercenaria mercenaria. Effect of Capitella (Cap) and Mercenaria (Merc) responses (time on surface, TOS), to disturbed muds (DM), disturbed sands (DS), control (undisturbed) muds (CM), control sands (CS), high ammonium, high oxygen (HAHO) and low ammonium, high oxygen (LAHO) core surfaces. Data for all quantities are means ( $\mathrm{n}=5$ replicate cores) and SDs. For each core, oxygen concentration is the mean of 4 surface measurements using an oxygen microelectrode. Ox: oxygen; Cap: Capitella sp. 1; Merc: $M$. mercenaria

water concentrations at ambient field levels. The expected and observed results for the orthogonal contrasts are summarized in Table 1.

Oxygen concentrations in the surface sediments did not follow the same pattern as the ammonium concentrations (Fig. 2). Highest concentrations were found in CM $\left(179 \mu \mathrm{mol} \mathrm{l}^{-1}\right), \mathrm{CS}\left(171 \mu \mathrm{mol} \mathrm{l}^{-1}\right)$ and LAHO $\left(163 \mu \mathrm{mol} \mathrm{l^{-1 }}\right)$ cores, followed by DS $\left(138 \mu \mathrm{mol} \mathrm{l^{-1 }}\right)$, HAHO $\left(137 \mu \mathrm{mol} \mathrm{l}^{-1}\right)$, and DM $\left(60 \mu \mathrm{mol} \mathrm{\textrm {l } ^ { - 1 }}\right)$ cores (Fig. 2). ANOVA showed significant differences among oxygen concentrations as a function of treatment $\left(\mathrm{p}=0.0008, F_{5,23}=6.35\right)$. Orthogonal contrasts supported the prediction that oxygen concentrations in DM cores would be significantly lower than all other treatments $(\mathrm{p}<0.0001, F=27.07$ ), and that oxygen concentrations in CM and CS cores would be statistically indistinguishable from DS cores as well as LAHO cores $(\mathrm{CM}+\mathrm{CS}=\mathrm{DS}, \mathrm{p}=0.5785, F=0.32 ; \mathrm{CM}+\mathrm{CS}=$ LAHO, $\mathrm{p}=0.0940, F=3.05$ ).

Oxygen profiles in the upper $2 \mathrm{~mm}$ within experimental cores, the region that new recruits explore, were consistent with gradients expected in control and disturbed sediments from different sedimentary regimes (e.g. Marinelli \& Woodin 2002) (Fig. 3). Highest concentrations were in CS and DS cores, followed closely by CM and then by DM. Oxygen concentrations in the manipulated HAHO and LAHO cores were also high (Fig. 3). 


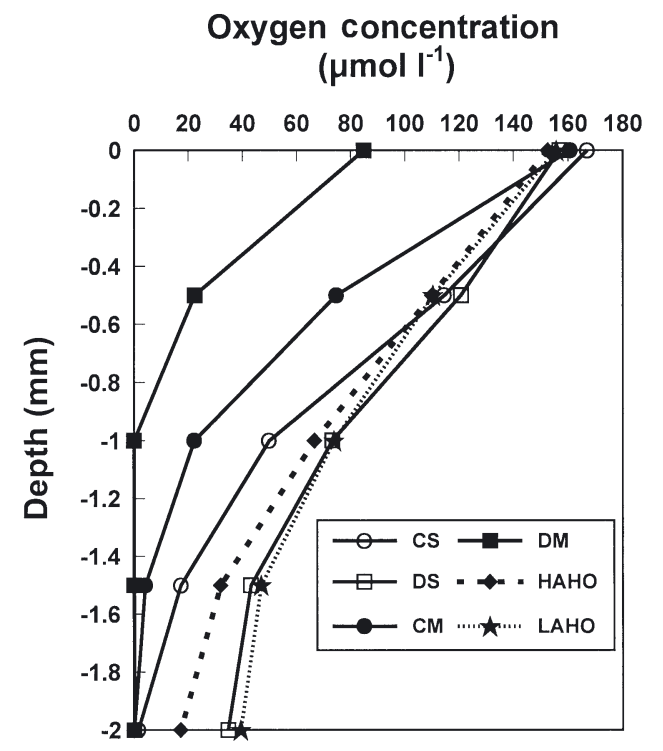

Fig. 3. Averaged oxygen profiles (across all replicates within a given treatment) for disturbed muds (DM), disturbed sands (DS), control muds (CM), control sands (CS), high ammonium, high oxygen (HAHO), and low ammonium, high oxygen (LAHO) cores, in the zone of exploration (top $2 \mathrm{~mm}$ ) that Capitella and Mercenaria new recruits explore. DM cores had lower surface and subsurface oxygen concentrations relative to the remaining treatments. Slightly higher oxygen concentrations in the DS, HAHO and LAHO cores may be due to mixing of overlying water into these permeable sediments during experimental manipulation

\section{Recruit responses}

Responses to sediment surfaces varied with species. For Mercenaria, longest average TOS was observed in DM (249 s) followed by DS (148 s), HAHO (39 s), CS (17 s), LAHO (17 s) and CM (8 s) (Fig. 2). For Capitella, surface exploration time was generally less than Mercenaria and the response trend was different. Longest average TOS occurred in DM (105 s) followed by HAHO (81 s), LAHO (11 s), DS (9 s), CM (8 s) and CS (5 s) (Fig. 2).

ANOVA showed significant effects of core treatments on TOS for Mercenaria: $\left(p=0.0037, F_{5,24}=4.76\right)$. For Mercenaria the data are strongly suggestive of a response to disturbance that may not be linked to the ammonium concentration (Fig. 2). For the disturbance control contrast $\mathrm{CM}+\mathrm{CS}=\mathrm{DS}$, TOS was significantly higher in disturbed cores $(\mathrm{p}=0.0061$, $F=9.03$ ), but there were no differences in this contrast for ammonium concentrations within the sediment (Table 1). These results suggest that some component of disturbance that is unrelated to ammonium concentration affects recruit behavior. Interestingly, there was a significant difference in TOS for the $\left[\mathrm{NH}_{4}{ }^{+}\right]$contrast $\mathrm{CM}+\mathrm{CS}+\mathrm{DS}+\mathrm{LAHO}=\mathrm{DM}+\mathrm{HAHO}(\mathrm{p}=0.0079$,
$F=8.41$ ). While this is consistent with the finding for ammonium for this contrast (above), it is less strongly significant due to high variance in Mercenaria behavior on DM and DS cores. Lastly, the manipulation control contrast CM + CS = LAHO was not significant $(\mathrm{p}=0.5396, F=0.39)$, consistent with a lack of a manipulation artifact. Taken together, these findings suggest that longer exploratory times are not uniquely associated with higher sediment ammonium levels or disturbance, but that both are potentially important (Table 1).

The analysis of TOS in the context of oxygenconcentration contrasts suggests that Mercenaria's exploratory behavior also may not be related uniquely to surface oxygen. For the disturbance control contrast $\mathrm{CM}+\mathrm{CS}=\mathrm{DS}$, no differences in surface oxygen concentration were observed, but a significant difference in TOS was detected ( $p=0.0061, F=9.03$ ), with longer exploratory times in the disturbed sand. For the oxygen + disturbance comparison $\mathrm{DM}=\mathrm{CS}+\mathrm{CM}+\mathrm{DS}+$ $\mathrm{HAHO}+\mathrm{LAHO}$, there was a significant difference in TOS ( $p=0.001, F=14.02$ ) as well as in oxygen concentration (Table 1, described above). These data indicate that the longer exploratory times may not be uniquely associated with lower oxygen concentration. Clearly, Mercenaria are responding to some other transient factor associated with disturbance.

ANOVA also showed significant effects of core treatments on TOS for Capitella $\left(\mathrm{p}=0.0053, F_{5,24}=4.43\right)$. The Capitella data, however, suggest that dissolved ammonium in the upper 2 to $3 \mathrm{~mm}$ of sediment significantly affects exploratory behavior (Fig. 2). For the orthogonal $\left[\mathrm{NH}_{4}{ }^{+}\right]$contrast $\mathrm{CM}+\mathrm{CS}+\mathrm{DS}+\mathrm{LAHO}=$ $\mathrm{DM}+\mathrm{HAHO}$, differences in both ammonium (Table 1, described above) and TOS ( $p=0.0003, F=17.5)$ were detected, with longer exploratory times associated with higher ammonium concentrations. Possibly, concentrations in DM and HAHO cores were above an acceptable limit, as we have argued previously (Woodin et al. 1998). The disturbance control contrast $\mathrm{CM}+\mathrm{CS}=\mathrm{DS}$ was not significant $(\mathrm{p}=0.3355, F=$ $0.97)$. This finding argues against an unquantified disturbance effect, in contrast to our findings for Mercenaria. Finally, no significant difference in TOS was found for the manipulation control contrast $\mathrm{CM}+\mathrm{CS}=$ LAHO ( $p=0.2453, F=1.42$ ). This is consistent with the absence of a manipulation effect (Table 1).

Finally, the orthogonal oxygen + disturbance contrast $\mathrm{DM}=\mathrm{CS}+\mathrm{CM}+\mathrm{DS}+\mathrm{HAHO}+\mathrm{LAHO}$ was significant both for oxygen (described above) and for Capitella TOS ( $\mathrm{p}=0.0008, F=14.61$ ). While this finding would argue for an effect of oxygen on recruit behavior, the disturbance-recovery experiment suggests that behavior does not covary with oxygen concentration per se (Fig. 1). 


\section{The importance of diagenetic cues among sedimentary regimes}

Results from the control and disturbed Oyster Landing cores supported the hypothesis that the strength of the disturbance effect, and the magnitude of the response, should vary with diagenetic regime. ANOVA for the oxygen data showed significant differences among treatments $\left(\mathrm{p}<0.0008, F_{5,23}=6.35\right)$ (Fig. 2), with significantly lower oxygen concentrations in disturbed muds relative to all other treatments $(\mathrm{p}=0.0001, F=$ 26.60 , Table 1). As noted above, oxygen concentrations in DS cores were statistically indistinguishable from CM and CS cores ( $p=0.0940, F=3.05$, Table 1). For ammonium, ANOVA showed significant differences among all treatments ( $\left.\mathrm{p}=0.0001, F_{5,24}=26.53\right)$, with concentrations in DM significantly higher than in the remaining treatments $(p=0.0168, F=6.60$, Table 1$)$. As discussed above, ammonium concentrations in DS cores were statistically indistinguishable from CM and CS cores ( $p=0.6745, F=0.18$, Table 1$)$. These findings are consistent with our expectations that disturbance signals vary as a function of the sedimentary regime.

\section{Mercenaria behavioral responses}

Mercenaria responses to the disturbed and control core surfaces also tended to support the suggestion that disturbance in muds has a greater effect on sediment acceptability relative to sands. Consistent, short initiation times $(<20 \mathrm{~s})$ were observed in CS and CM surfaces. Longer exploratory times were noted in disturbed sands $(\sim 150 \mathrm{~s})$, with longest TOS in disturbed muds ( 250 s). The ANOVA for TOS revealed a significant difference in treatment effects $(p=0.0037$, $\left.F_{5,24}=4.76\right)$. Significant differences were also found for the orthogonal contrasts $\mathrm{DM}=\mathrm{DS}+\mathrm{CM}+\mathrm{CS}(\mathrm{p}=$ $0.0015, F=12.85)$ and $\mathrm{CM}+\mathrm{CS}=\mathrm{DS}(\mathrm{p}=0.0061, F=$ 9.03). These findings support the suggestion that disturbance in muds has the greatest effect on sediment acceptability, but that disturbance in sand also affects behavior for Mercenaria.

\section{Capitella behavioral responses}

Capitella responses were consistent with the model predictions, i.e. acceptance of low ammonium-high oxygen surfaces associated with CM, DS and CS environments, and rejection of high ammonium-low oxygen surfaces associated with DM environments. The times between arrival on the sediment surface and burrowing into the sediments were generally below $10 \mathrm{~s}$ for the CS, CM and DS treatments (Fig. 2). Sub- stantially longer exploration times $(\sim 110 \mathrm{~s})$ were evident in the DM surfaces. ANOVA for treatment effects was significant $\left(\mathrm{p}=0.0053, F_{5,24}=4.43\right)$, and the orthogonal contrast for the importance of disturbance in muds relative to sands $(\mathrm{DM}=\mathrm{DS}+\mathrm{CM}+\mathrm{CS})$ was highly significant ( $p=0.0002, F=18.46)$. As discussed previously, the orthogonal contrast comparing responses to DS relative to CM and CS $(\mathrm{DS}=\mathrm{CM}+\mathrm{CS})$ was not significant ( $\mathrm{p}=0.3355, F=0.97$ ).

\section{DISCUSSION}

\section{Disturbance, habitat selection and community structure}

Disturbance can enhance success if previously occupied resources, such as food or space, become available to extant or prospecting individuals (Connell 1970, Clark 1991, Wethey et al. 2001). Alternatively, disturbance can have lethal or sublethal effects that may reduce survivorship and/or reproductive success (Breitburg 1992). In sedimentary systems, disturbance can include large-scale sediment transport events or small-scale biogenic disturbances, both of which can cause mortality for new recruits (Wilson 1980, Luckenbach 1984, Murphy 1985, Hines et al. 1989, Woodin \& Marinelli 1991). These disruptions also cause shifts of meiofaunal distributions (Thistle et al. 1999), microbial dynamics (Findlay et al. 1990), particulate distributions, and/or alteration of the concentration of porewater constituents (Marinelli 1992), all of which serve as potential 'cues'. Our evidence suggests that disturbance cues that promote avoidance are highly transient and associated with the dissolved phase. An important question is whether avoidance confers a selective advantage, particularly if disturbed areas are associated with active conspecific adults.

Biogenic disruptions that cause mortality, including surface deposit-feeding activity and deposition of mounds and tailings, occur persistently on local spatial scales (Krager \& Woodin 1993, Marinelli 1994), are patchily distributed, and have consequences that are particularly grave for new juveniles (Woodin \& Marinelli 1991 and references therein). Compounding this problem, many infauna that disrupt sediments are mobile on spatial scales of $\mathrm{cm}$ to $\mathrm{m}$, and on time scales of d to wk throughout life (e.g. Gunther 1992, Marinelli 1994, Stocks 2002), adding complexity to the problem of predicting the location and frequency of disturbance. However, new recruits are perhaps the most vagile, as they are small and positioned opportunely near the sediment-water interface. Our early observations (Woodin et al. 1995), and other experimental results (e.g. Butman et al. 1988, Snelgrove et al. 1993) suggest that in 
weak flows, small fauna can easily move locally, e.g. on the cm scale, as well as distantly (Palmer 1988, Stocks 2002). Thus, avoidance of disturbed areas by new recruits, and local movement to a more favorable area (Snelgrove et al. 2001a), may enhance survival in a habitat where adult conspecifics thrive. If this model is correct, then sedimentary environments can be viewed as mosaics in the temporal as well as spatial sense, with significant geochemical complexity both driving, and resulting from, local disturbances and shifts in patterns of abundance. Predation, competition, foraging activities, and other processes promoting migration or mortality act in concert to modify patterns of abundance in the postsettlement stages, further complicating the landscape. In spite of these diverse processes and inherent risks, there is evidence for consistency between recruitment and adult density for both Capitella sp. 1 and Spisula solidissima (Snelgrove et al. 1999), suggesting that settlement patterns can persist through time. These choices are not necessarily optimal, but perhaps merely sufficient to insure survival. For example, Capitella sp. 1 has been shown to metamorphose most rapidly in substrates that are less optimal for growth and reproductive success (Cohen \& Pechenik 1999).

\section{Disturbance, recovery and Capitella}

Organic matter concentrations, microbial populations and infaunal activities co-act to produce a spatially heterogeneous and transient sedimentary matrix (e.g. Thistle et al. 1984, Meyers et al. 1988). Given this complexity, bulk measures of sediment qualities, e.g. organic carbon concentration and grain size, do not adequately describe the geochemical environment in which an organism operates. As such, it may be difficult to reconcile species responses with specific cues if only the larger biogeochemical landscape is considered. This may be particularly true for the well studied Capitella, as many linkages between Capitella abundance and the bulk geochemical environment have been identified, and some results are conflicting.

We expected that Capitella might be less sensitive to disrupted surfaces, given its reputation as an opportunistic species prevalent in disturbed and eutrophic environments (Grassle \& Grassle 1974, Pearson \& Rosenberg 1978), its preference for solute-rich muds relative to clean sands in experimental trials (Butman \& Grassle 1992), and its relatively high growth rates in nitrogen-rich environments (Tenore et al. 1984). Indeed, our previous studies with the polychaete Arenicola and the bivalve Mercenaria (Marinelli \& Woodin 2002) have shown strong, negative relationships between changing surface oxygen concentration and surface exploratory time. The results for Capitella, however, are consistent with neither our prior results nor a positive response to disturbance, as longer exploratory times persisted in fully recovered (as defined by surface oxygen concentration) disturbed cores (Fig. 1). Cohen \& Pechenik (1999) demonstrated rapid metamorphic responses for Capitella sp. 1 in lower organic content natural sands compared to sediments with higher organic content-this is consistent with a preference for cleaner, undisturbed habitats as suggested by the disturbance-recovery results. Our findings therefore conflict with the expectation that the avoidance cue is a solute with similar distributions and reaction kinetics as oxygen and other solutes (Woodin et al. 1998). Rather, they suggest that the avoidance cue may be associated with the particulate phase, or a solute with very different reaction time scales than oxygen (Marinelli \& Woodin 2002).

By contrast, our manipulation experiments suggest that ammonium is an important substance for Capitella. The duration of exploratory behavior was positively related to ammonium concentration, i.e. longest exploratory times were found in DM and HAHO surfaces, whereas TOS in remaining, low ammonium treatments was uniformly short. Unfortunately, we did not measure ammonium concentration in our disturbance-recovery experiment with Capitella. Interestingly, a portion of ammonium in sediments is adsorbed onto particles, and this raises the possibility that adsorption-desorption reactions, as well as absolute ammonium concentration, were important, unmeasured factors in our disturbancerecovery trials. Possibly, adsorbed ammonium in 'recovered' sediments may have desorbed due to the disturbance, and if so, this desorbed ammonium may have driven the rejection response. This scenario is consistent with negative recruitment effects in sediments reworked by adult Capitellids (Snelgrove et al. 2001b), as bioturbational disruption can facilitate ammonium release. Future studies clearly should consider both the dissolved and adsorbed phase.

Other evidence linking positive Capitella sp. 1 responses to sulfides (Cuomo 1985), or organic matter concentration (Dubilier 1988), show that even for one species, infaunal interactions with biogeochemical components can be varied and difficult to isolate. Although we did not measure sulfide, our relatively high levels of oxygen suggest that sulfide was not a factor in any of the experiments. If it was, we would expect greater settlement in the disturbed muds, but this was not the case. Dubilier's experiments (1988) suggest that sulfide does not promote recruitment, but rather, organic-rich sediment is sufficient to promote selection of a habitat. This is consistent with the results of Butman \& Grassle (1992) and Grassle et al. (1992), who noted preferential selection of muds over azoic glass beads. Marsh et al. (1989) suggested that positive 
recruitment responses may be less related to total organic carbon and nitrogen, and more related to micronutrients or trace quantities. This has been demonstrated for positive cues such as peptides (Zimmer-Faust \& Tamburri 1994) and negative cues such as brominated compounds (Woodin et al. 1993). For all such substances, it is important to characterize their dynamic properties in sediments, including reaction kinetics and transport properties, as well as environmental concentrations relative to response thresholds (e.g. Coon et al. 1990), on the scales at which organisms operate. Without this information, we cannot fully evaluate the ecological consequences of recruitment cues in the heterogeneous sedimentary milieu.

\section{Mercenaria responses to disturbance cues}

The results for Mercenaria strongly suggest an unresolved disturbance effect (e.g. CM + CS = DS, with no significant differences in oxygen or ammonium concentrations, but very significant changes in TOS in DS) (Table 1). However, ammonium may also play a role, as indicated by the significant contrast $\mathrm{CM}+\mathrm{CS}+\mathrm{DS}+$ $\mathrm{LAHO}=\mathrm{DM}+\mathrm{HAHO}($ Table 1$)$. Our previous experiments with Mercenaria showed that exploratory behavior was inversely related to oxygen concentration (Marinelli \& Woodin 2002). The data presented above are partially consistent with this previous finding, i.e. a significant difference was observed in the contrast CM $+\mathrm{CS}+\mathrm{DS}+\mathrm{HAHO}+\mathrm{LAHO}=\mathrm{DM}$, which tests an 'oxygen effect'. Unfortunately the oxygen effect is caused by disturbance and, as such, we cannot separate the influence of oxygen vs. disturbance on behavior. As we have argued for Capitella, there are a plethora of substances, both dissolved and adsorbed, that may affect recruitment decisions, and it is possible that sediments used in our previous experiments differed from those used above in some unforeseen way that affected Mercenaria responses. This seems unlikely given the cosmopolitan distribution of the clams and their presence at the sites of sediment collection, but it cannot be ruled out. It is also is possible that larval age contributed to variation in response (e.g. Bachelet et al. 1992); however, we were careful to select organisms that had lost their velum within the previous $24 \mathrm{~h}$. Our direct observations confirmed the adoption of a benthic existence.

\section{The importance of sedimentary regime}

In spite of our mixed findings, it remains clear that disturbance can negatively affect recruitment, and that the disturbance effect is most pronounced in muddy environments. Our disturbance-recovery model pre- dicted that environments with steep gradients (generally muds with higher organic carbon and nitrogen contents) are likely to provide a larger disturbance signal than environments characterized by shallow gradients (generally sands with comparatively low organic content). This prediction generally held true, i.e. we found higher ammonium and lower oxygen concentrations in DM surfaces relative to all other core surfaces (Table 1). Accordingly, longest exploratory times occurred in DM cores (Fig. 2). However, the relatively long TOS for Mercenaria in DS cores, and the persistence of the long exploratory times noted for Capitella in the $5 \mathrm{~h}$ recovery cores, suggests that the simple porewater explanation advanced in our original model should be expanded upon. Such an expansion might incorporate more complex kinetics, changes in microbial dynamics, or changes in organic characteristics associated with the particulate phase, as discussed with ammonium above.

\section{Importance of still-water experiments}

Our experiments, conducted in still water, were designed to examine behavioral responses under controlled conditions and provide insight into: (1) how rapidly organisms evaluate habitats, (2) what conditions promote acceptance or rejection, and (3) how the acceptance or rejection response facilitates residence within, or departure from, a habitat. They do not predict how an organism arrives at a site, but they provide valuable information concerning the conditions that promote successful establishment within a given locale. Such information is critical to evaluating recruitment patterns in sedimentary environments, and the extent to which recruitment intensity, i.e. the 'supply side', affects community dynamics.

\section{Conclusions}

We have shown that small-scale geochemical processes have important, time-dependent effects on recruitment for 2 widely distributed species, and have argued that many of these processes are under biological control. An important avenue for future research is to define the operative substances and the processes that control their distribution, so that a fuller understanding of recruitment success, and its contribution to patterns of abundance, can be achieved.

Acknowledgements. We thank Dr. J. Grassle and Ms. J. Rosario for kindly providing the seed individuals for the Capitella culture, and SeaPerfect Sea Farms for providing the Mercenaria larvae. Ms. D. Hatcher and Ms. D. Edwards 
assisted with the many aspects of the experiments. Mr. C. Robertson analyzed the sediment for organic carbon and nitrogen. Critical comments on earlier drafts were provided by Ms. H. Stapleton, Mr. G. Waldbusser, and Mr. S. Engstrom. The authors are grateful to the National Science Foundation for support of this research (OCE 0049065 to RLM and OCE 9811435 to SAW), and to the Skidaway Institute of Oceanography and Baruch Marine Field Laboratory for use of the research facilities.

\section{LITERATURE CITED}

Andre C, Rosenberg R (1991) Adult-larval interactions in the suspension-feeding bivalves Cerastoderma edule and Mya arenaria. Mar Ecol Prog Ser 71:227-234

Bachelet G, Butman CA, Webb CM, Starczak VR, Snelgrove PVR (1992) Non-selective settlement of Mercenaria mercenaria (L.) larvae in short-term, still-water, laboratory experiments. J Exp Mar Biol Ecol 161:241-280

Beukema JJ, DeVlas J (1979) Population parameters of the lugworm, Arenicola marina, living on tidal flats on the Dutch Wadden Sea. Neth J Sea Res 13:331-353

Breitburg DL (1992) Episodic hypoxia in Chesapeake Bay: interacting effects of recruitment, behavior and physical disturbance. Ecol Monogr 62:525-546

Burke RD (1986) Pheromones and the gregarious settlement of marine invertebrate larvae. Bull Mar Sci 39:323-331

Butman CA, Grassle JP (1992) Active habitat selection by Capitella sp. I larvae. I. two-choice experiments in still water and flume flows. J Mar Res 50:669-715

Butman CA, Grassle JP, Webb CM (1988) Substrate choices made by marine larvae settling in still water and in a flume flow. Nature 333:771-773

Clark JS (1991) Disturbance and tree life history on the shifting mosaic landscape. Ecology 72:1102-1118

Cohen RA, Pechenik JA (1999) Relationship between sediment organic content, metamorphosis, and postlarval performance in the deposit-feeding polychaete Capitella sp. 1. J Exp Mar Biol Ecol 240:1-18

Commito JA, Thrush SF, Pridmore RD, Hewitt JE, Cummings VJ (1995) Dispersal dynamics in a wind-driven system. Limnol Oceanogr 40:1513-1518

Connell JH (1970) On the role of natural enemies in preventing competitive exclusion in some marine animals and in rain forest trees. In: den Boer PJ, Gradwell GR (eds) Proceedings of the Advanced Study Institute on Dynamics of Numbers on Populations, Oosterbeek, Sep 7-18, 1970. Pudoc, Wageningen, p 298-312

Coon SL, Walch M, Fitt WK, Weiner RM, Bonar DB (1990) Ammonia induces settlement behavior in oyster larvae. Biol Bull 179:297-303

Cuomo MC (1985) Sulphide as a larval settlement cue for Capitella sp. I. Biogeochem 1:169-181

Diaz RJ, Rosenberg R (1995) Marine benthic hypoxia: a review of its ecological effects and the behavioral responses of macrofauna. Oceanogr Mar Biol Annu Rev 33:245-303

Dubilier N (1988) $\mathrm{H}_{2} \mathrm{~S}$ - A settlement cue or a toxic substance for Capitella sp. I larvae? Biol Bull 174:30-38

Eckelbarger KJ (1974) Population biology and larval development of the terebellid polychaete Nicolea zostericola. Mar Biol 27:101-113

Eckman JE (1983) Hydrodynamic processes affecting benthic recruitment. Limnol Oceanogr 28:241-257

Emerson CW, Grant J (1991) The control of soft-shell clam (Mya arenaria) recruitment on intertidal sandflats by bedload sediment transport. Limnol Oceanogr 36:1288-1300
Fanning KA, Carder KL, Betzer PR (1982) Sediment resuspension by coastal waters: a potential mechanism for nutrient re-cycling on the ocean's margins. Deep-Sea Res 29: 953-965

Findlay RH, Trexler MB, Guckert JB, White DC (1990) Laboratory study of disturbance in marine sediments: response of a microbial community. Mar Ecol Prog Ser 62:121-133

Finelli CM, Pentcheff ND, Zimmer RK, Wethey DS (2000) Physical constraints on ecological processes: a field test of odor-mediated foraging. Ecology 81:784-797

Grassle JF, Grassle JP (1974) Opportunistic life histories and genetic systems in marine benthic polychaetes. J Mar Res 32:253-284

Grassle JP, Butman CA, Mills SW (1992) Active habitat selection by Capitella sp. I Larvae. II. Multiple choice experiments in still water and flume flows. J Mar Res 50:717-743

Green MA, Jones ME, Boudreau CL, Moore RL, Westman BA (2004) Dissolution mortality of juvenile bivalves in coastal marine sediments. Limnol Oceanogr (in press)

Gunther CP (1992) Dispersal of intertidal invertebrates; a strategy to react to disturbance of different scales? Neth J Sea Res 30:45-56

Hardege JD, Bentley MG (1997) Spawning synchrony in Arenicola marina: evidence for sex pheromonal control. Proc R Soc Lond B 264:1041-1047

Hardege JD, Bentley MG, Snape L (1998) Sediment selection by juvenile Arenicola marina. Mar Ecol Prog Ser 166: 187-195

Hiddink JG, Wolff WJ (2002) Changes in distribution and decrease in numbers during migration of the bivalve Macoma balthica. Mar Ecol Prog Ser 233:117-130

Highsmith RC (1982) Induced settlement and metamorphosis of sand dollar (Dendraster excentricus) larvae in predatorfree sites: adult sand dollar beds. Ecology 63:329-337

Hines AH, Posey MH, Haddon PJ (1989) Effects of adult suspension- and deposit-feeding bivalves on recruitment of estuarine infauna. Veliger 32:109-119

Huettel M, Ziebis W, Forster S (1996) Flow-induced uptake of particulate matter in permeable sediments. Limnol Oceanogr 41:309-322

Huxham M, Richards M (2003) Can postlarval bivalves select sediment type during settlement? A field test with Macoma balthica (L.) and Cerastoderma edule (L.). J Exp Mar Biol Ecol 288:279-293

Koroleff F (1976) Determination of $\mathrm{NH}_{4}$-N. In: Grasshoff K (ed) Methods of seawater analysis. Verlag Chemie, Weinheim, p 127-133

Krager CD, Woodin SA (1993) Spatial persistence and sediment disturbance of an arenicolid polychaete. Limnol Oceanogr 38:509-520

Luckenbach MW (1984) Settlement and early post-settlement survival in the recruitment of Mulinia lateralis (Bivalvia). Mar Ecol Prog Ser 17:245-250

Marinelli RL (1992) Effects of polychaetes on silicate dynamics and fluxes in sediments: importance of species, animal activity and polychaete effects on benthic diatoms. J Mar Res 50:745-779

Marinelli RL (1994) Effects of burrow ventilation on activities of a terebellid polychaete and silicate removal from sediment porewaters. Limnol Oceanogr 39:303-317

Marinelli RL, Woodin SA (2002) Experimental evidence for linkages between infaunal recruitment, disturbance and sediment chemistry. Limnol Oceanogr 47:221-229

Marinelli RL, Jahnke RA, Craven DB, Nelson JR, Eckman JE (1998) Sediment nutrient dynamics on the South Atlantic Bight continental shelf. Limnol Oceanogr 43:1305-1320 Marsh AG, Gremare A, Tenore KR (1989) Effect of food type 
and ration on growth of juvenile Capitella sp. 1 (Annelida, Polychaeta): macro- and micronutrients. Mar Biol 102: 519-527

Meyers MB, Powell EN, Fossing H (1988) Movement of oxybiotic and thiobiotic meiofauna in response to changes in porewater oxygen and sulfide gradients around macroinfaunal tubes. Mar Biol 98:395-414

Miller DC, Sternberg RW (1988) Field measurements of the fluid and sediment-dynamic environment of a benthic deposit feeder. J Mar Res 46:771-796

Murphy M (1985) Factors affecting the distribution of the introduced bivalve, Mercenaria mercenaria, in a California lagoon - the importance of bioturbation. J Mar Res 43: 673-692

Osman RW, Whitlatch RB, Malatesta RJ (1992) Potential role of micro-predators in determining recruitment into a marine community. Mar Ecol Prog Ser 83:35-43

Palmer MA (1988) Dispersal of marine meiofauna: a review and conceptual model explaining passive transport and active emergence with implications for recruitment. Mar Ecol Prog Ser 48:81-91

Pawlik JR (1992) Chemical ecology of the settlement of benthic marine invertebrates. Oceanogr Mar Biol Annu Rev 30:273-335

Pearson TH, Rosenberg R (1978) Macrobenthic succession in relation to organic enrichment and pollution of the marine environment. Oceanogr Mar Biol Annu Rev 16:229-311

Revsbech NP, Jorgensen BB, Brix O (1981) Primary production of microalgae in sediments measured by oxygen microprofile, $\mathrm{H}^{14} \mathrm{CO}_{3}^{-}$fixation and oxygen exchange methods. Limnol Oceanogr 26:717-730

Ross DJ, Johnson CR, Hewitt CL (2003) Variability in the impact of an introduced predator (Asterias amurensis: Asteroidea) on soft-sediment assemblages. J Exp Mar Biol Ecol 288:257-278

Snelgrove PVR, Butman CA, Grassle JP (1993) Hydrodynamic enhancement of larval settlement in the bivalve Mulinia lateralis (Say) and the polychaete Capitella capitata sp. I in microdepositional environments. J Exp Mar Biol Ecol 168:71-109

Snelgrove PVR, Grassle JP, Grassle JF, Petrecca RF, Ma $H$ (1999) In situ habitat selection by settling larvae of marine soft-sediment invertebrates. Limnol Oceanogr 44: $1341-1347$

Snelgrove PVR, Grassle JF, Grassle JP, Petrecca RF, Stocks KI (2001a) The role of colonization in establishing patterns of community composition and diversity in shallow-water sedimentary communities. J Mar Res 59:813-830

Snelgrove PVR, Grassle JP, Zimmer CA (2001b) Adult macrofauna effects on Capitella sp. I larval settlement: a laboratory flume study. J Mar Res 59:657-674

Editorial responsibility: Kenneth Tenore (Contributing Editor), Solomons, Maryland, USA
Stocks KI (2002) Flume experiments on post settlement movement in polychaetes. J Mar Res 60:743-762

Suer AL, Phillips DW (1983) Rapid, gregarious settlement of the larvae of the marine echiuran Urechis caupo Fisher and MacGinitie 1928. J Exp Mar Biol Ecol 67:243-259

Tenore KR, Hanson RB, McClain J, MacCubbin AE, Hodson RE (1984) Changes in compositon and nutritional value to a benthic deposit feeder of decomposing detritus pools. Bull Mar Sci 35:299-311

Thamdrup B, Fossing H, Jorgensen BB (1994) Manganese, iron, and sulfur cycling in a coastal marine sediment, Aarhus Bay, Denmark. Geochim Cosmochim Acta 58(23): $5115-5129$

Thayer CW (1983) Sediment-mediated biological disturbance and the evolution of marine benthos. In: Tevesz MJS, McCall PL (eds) Biotic interactions in recent and fossil benthic communities. Plenum Press, New York, p 480-625

Thistle D, Reidenauer JA, Findlay RH, Waldo R (1984) An experimental investigation of enchanced harpacticoid (Copepoda) abundances around isolated seagrass shoots. Oecologia 63:295-299

Thistle D, Levin LA, Gooday AJ, Pfannkuche O, Lambshead PJD (1999) Physical reworking by near bottom flow alters the metazoan meiofauna of fieberling Guyot (northeast Pacific). Deep-Sea Res 46:2041-2052

Wethey DS, Lindsay SM, Woodin SA, Marinelli RL (2001) Population consequences of intermediate disturbance: recruitment, browsing predation and geochemistry. In: Aller JY, Woodin SA, Aller RC (eds) Animal-sediment interactions. University of South Carolina Press, Columbia, p 141-158

Wilson WH (1980) A laboratory investigation of the effects of a terebellid polychaete on the survivorship of nereid polychaete larvae. J Exp Mar Biol Ecol 46:73-80

Wilste WI (1980) Effects of Polinices duplicatus (Gastropoda: Naticidae) on infaunal community structure at Barnstable Harbor, Massachusetts, USA. Mar Biol 56:301-310

Woodin SA, Marinelli RL (1991) Biogenic habitat modification in marine sediments: the importance of species composition and activity. Symp Zool Soc Lond 63:231-250

Woodin SA, Marinelli RL, Lincoln DE (1993) Allelochemical inhibition of recruitment in sedimentary assemblages. J Chem Ecol 19:517-530

Woodin SA, Lindsay SM, Wethey DS (1995) Process-specific cues in marine sedimentary systems. Biol Bull 189:49-58

Woodin SA, Marinelli RL, Lindsay SM (1998) Process-specific cues for recruitment in sedimentary environments: geochemical signals? J Mar Res 56:535-558

Zimmer-Faust RK, Tamburri MN (1994) Chemical identity and ecological implications of a waterborne, larval settlement cue. Limnol Oceanogr 39:1075-1087

Submitted: August 20, 2003; Accepted: December 16, 2003 Proofs received from author(s): March 8, 2004 